\section{Developing oncology clinical practice through education}

\author{
by Mary Flaherty
}

\section{Abstract}

The advent of complex and multiple treatments in cancer care and the subsequent impact on the patient and family have increased the need for murses to be both technically and interpersonally competent. The course in oncology nursing at the Royal Victoria Hospital in Montreal provides practising murses with an opportunity to develop their knowledge and skills in oncology nursing. This eight-week full-time course focuses on the experience of cancer for adult patients and their families. While traditional approaches assign students to specific clinical units, this course has students follow selected patients and families as they move between home and hospital settings.

The development process, content, learning activities and evaluation methods of the course are described. Distinctive features, including self-directed learning experiences, one-to-one work with an advisor, and the family as a unit of care are highlighted. Future directions for oncology mursing education at this institution are suggested.

\section{Introduction}

The care of patients with cancer and their families has become increasingly complex. Cancer treatment encompasses multiple modalities, including combinations of surgery, chemotherapy, radiation therapy and immunotherapy. Nurses play a major role in each of these treatment modalities. In addition, oncology nurses are engaged in skilfully managing disease symptoms and side effects of treatment (Miaskowski, 1990).

The advent of new treatments and technologies has increased the need for nurses to be both technically and interpersonally competent. The development of oncology nurses through education is essential to the quality of care received by patients with cancer (Itano, Pierce, Masten \& Whitley, 1992). In basic nursing education programs, the inclusion of substantial cancer-related content has been recommended (Canadian Association of Nurses in Oncology, 1990). In addition, nurses who work with patients with cancer require advanced knowledge through continuing education in order to be effective practitioners. Therefore, specialized oncology courses or programs should be presented to assist nurses to develop the knowledge, attitudes and skills required to provide competent nursing care.

In order to address the educational needs of both nursing students and practising nurses regarding cancer care, oncology courses and programs have been developed and implemented in universities, colleges and hospitals (Nielsen \& Miaskowski, 1987; Nevidjon \& Deatrich, 1985; Quinn-Casper \& Holmgren, 1987; Stolte, Goss \& Lim, 1988; Valencius, 1980a, 1980b). The content, teaching strategies and evaluation methods of these programs vary according to the program goals and target audience.

At the Royal Victoria Hospital, a large tertiary care teaching hospital located in Montreal, patients with cancer are cared for in oncology, palliative care, surgical, and medical units. Outpatient oncology and palliative home care services are also provided. Regular staff development sessions and workshops have assisted nurses to keep abreast of changes in practice. However, it was found that brief sessions did not afford adequate time to address the complex and multiple issues involved in nursing this patient population. Therefore, oncology nursing administrators and educators at the Royal Victoria Hospital determined that a full-time course might permit nurses to step away from their usual roles and responsibilities and examine their clinical practice. It was anticipated that this examination of practice could result in long-term benefits.

A course in oncology nursing was initiated in October 1990. The course is now offered twice per year, in the fall and winter months. This paper describes the development process, course content, learning activities and course evaluation methods. Future directions in oncology nursing education in this agency are also discussed.

\section{Course development process}

A planning committee spearheaded the project. Members included the director of continuing education in nursing, head nurses, nurse educators and consultants specialized in medical, surgical and gynecological oncology, palliative care and family nursing. The curriculum was formulated from data generated by an assessment of the learning needs of staff, an examination of the philosophy and conceptual framework of the department of nursing, a literature review and brainstorming by the committee.

\section{DÉVELOPPER LA PRATIQUE CLINIQUE DES SOINS INFIRMIERS PAR LE BIAIS DE L'ÉDUCATION}

\section{ABRÉGÉ}

L'avènement de traitements complexes et multiples en oncologie et l'impact subséquent qu'ils ont sur le patient et sa famille ont accentué le besoin qu'ont les infirmières d'être compétentes à la fois aux niveaux technique et interpersonnel. Le cours de Nursing oncologique du Royal Victoria Hospital de Montréal offre aux infirmières praticiennes l'occasion de développer leurs connaissances et leurs aptitudes en nursing oncologique. Ce cours à plein temps de huit semaines s'intéresse plus particulièrement à l'expérience du cancer des patients adultes et de leur famille. Et tandis qu'une approche traditionnelle enverrait les infirmières dans des services cliniques spécifiques, ce cours demande aux étudiantes de suivre des patients sélectionnés et leur famille au gré de leurs passages entre le cadre des soins à domicile et celui des soins hospitaliers.

On y décrit le processus de développement, le contenu, les activités d'apprentissage et les méthodes d'évaluation du cours. On y souligne les caractéristiques originales, y compris les expériences d'apprentissage autodirigé, le travail en tête-à-tête avec un conseiller, et, la famille en tant que cadre de soins. On y suggère enfin les directions futures que cet établissement entrevoit pour le nursing oncologique.

Mary Flaherty, RN, MSc(A), is a nurse clinician teacher at the Royal Victoria Hospital, Montreal. 


\section{Literature review}

The literature review revealed two teaching models for oncology nurses. Stolte, Goss and Lim (1988) reported on a three-month residency program offered in an ambulatory care setting. Course content included nursing of clients by settings and functions, specific disease site, and nursing issues such as body image and symptom control. Nielsen and Miaskowski (1987) described a university-based continuing education program offered over a two-year period. The revised curriculum included courses on cancer treatment, the psychosocial impact of cancer, nursing diagnoses, oncologic emergencies, legal/ethical issues and specific diseases by cancer site. Both programs used a self-directed learning approach in which students were assisted to develop their own learning objectives. Learning methods included classroom and clinical work, as well as library study.

The program planning committee also examined the format and content of oncology nursing textbooks (Carnevali \& Reiner, 1990; Groenwald, 1987; Snyder, 1986; Ziegfield, 1987). In the text, The Cancer Experience: Nursing Diagnosis and Management, Carnevali \& Reiner (1990) describe the problems and issues for patients and families in managing daily living throughout the cancer experience. This focus was recognized as one that matched our own philosophy.

\section{Assessment of staff learning needs}

Members of the planning committee held small group discussions with nurses working in general and specialized oncology units and in the outpatient oncology clinic. Through exploration of the difficulties that nurses experienced in their work, the groups identified their

\section{Table One: Staff learning needs}

Communication with cancer patients

Death and dying issues

Resources to help nurses cope

Ethical issues (eg. truth telling)

Working within the multidisciplinary team

Pharmacology \& administration of antineoplastic drugs

Symptom management

\section{Figure One: Guidelines for advisors}

\section{Overall goal}

The role of the advisor is to facilitate learning by helping the student in the selection of appropriate patients and families and by providing ongoing supervision and direction of clinical care.

\section{Objectives}

The advisor will:

1. Assist the student in the selection of a patient and family based on student's learning needs, knowledge of patient condition and family situation, collaboration of other team members and other factors such as frequency of patient contact and patient distance from the hospital.

2. Meet weekly with the student to review and direct clinical practice and to give clinical feedback.

3. Ensure that the student knows whom to contact for all clinical aspects of the patient's care.

4. Gather data for the student's evaluation and complete the evaluation.

5. Meet weekly with the advisor group to discuss clinical learning (supervision) issues with a particular emphasis on the involvement of the student with the family. learning needs. The results are summarized in Table One.

The planning committee determined that the course should focus on the collaborative efforts of nurses, patients and families in order to promote health. Thus, patients and families are recognized as partners in care and emphasis is placed on understanding their experience of living with cancer.

\section{Philosophical approach and conceptual model}

The goals and content of the course were guided by the statement of nursing practice of the Department of Nursing of the Royal Victoria Hospital and the McGill Model of Nursing. According to our statement of nursing practice, the health of both individuals and families is the focus of nursing practice. Health is evidenced by the individual's and family's ability and potential to adapt to stressors, crises and daily life events. The person (patient), as described in the McGill Model of Nursing, is a problem-solver, capable of learning new ways of coping with situations and problematic events. Solutions to problems are therefore thought to arise from within the family and not to emanate from the nurse. Consequently, active participation of the patient and family are needed for the patient/family goals to be achieved (Gottlieb \& Rowat, 1987).

\section{Course in oncology nursing}

\section{Format}

The course is now offered as an eight-week full-time course which is open to all licensed nurses expressing an interest in developing knowledge and skills in oncology nursing. Previous experience in oncology is not a requirement. Nurses do not need to be employed by the Royal Victoria Hospital. Although a registration fee is charged to nurses from other institutions, bursaries are available to all nurses interested in joining our hospital. Funding for educational bursaries is provided by the department of nursing and the Cedars Cancer Institute at the Royal Victoria Hospital. Our own nursing staff are granted educational leaves to pursue the course and are replaced by unit-based availability staff.

The planning committee elected to use a self-directed learning approach in which nurses focus on their particular learning needs and interests. Since not all nurses are accustomed to directing their own learning, students must be matched with an advisor who works with them on a one-to-one basis to individualize the program. The planning committee developed guidelines to assist the advisor (Figure One). The guidelines clarified the role of the advisor in facilitating and evaluating learning and in ensuring safe practice. One nurse coordinator organized the daily activities of the course, as well as the selection of students and promotion of the course.

The overall goals for the eight-week course are for the nurse to: 1. Understand the experience of living with cancer for the patient and the family

2. Develop knowledge of pathophysiology, diagnostic tests and therapeutic regimes

3. Develop knowledge and skills to nurse patients and families

4. Understand collaborative practice within the multidisciplinary team

5. Develop personal resources to cope with their own feelings about nursing patients with cancer

6. Explore professional issues in nursing in oncology

\section{Content and learning strategies}

Specific objectives, content and learning strategies were developed for each of the overall course goals and will be discussed in the following paragraphs. The objectives follow the nursing process whereby nurses develop their abilities to assess, plan and intervene with patients and families, and evaluate the outcomes of nursing interventions.

Learning strategies included clinical practice, classroom work, reading and critiquing the literature, and written and oral 
assignments. Students selected clinical areas in relation to their clinical learning objectives. They were allowed the choice to work in one clinical area or in a combination of settings. Clinical settings included specialized oncology units: Hematology/medicine, surgery, gynecology, palliative care; the oncology ambulatory care centre; and medical and surgical units. Students could follow a single patient/family through a variety of clinical settings including home, or they could follow several patients in one or more settings. Regardless of the setting, emphasis was placed on caring for the patient and family over time so that students could examine the impact of the cancer experience on the patient and family as well as implications for practice. During the three days per week of clinical practice, students worked closely with the primary nurse and other members of the multidisciplinary team.

Classroom learning encompassed a variety of teaching methods. This repertoire included lectures with discussion, panel presentations, clinical seminars, role-playing with videotaping and skill labs. The following sections describe the course content and learning activities in relation to each of the course goals and the method of student evaluation.

\section{Understanding the experience of living with cancer}

Content was developed to address the patient and family perspective of living with cancer. Patients and family members were invited to participate as faculty to share their experiences. They participated in classes on understanding the impact of cancer, sexuality, coping with body image changes, living with AIDS and survivorship and hope. The messages that patients gave during these sessions included the importance of listening to and believing the patient, being honest and providing requested information.

This kind of presentation heightened the nurses' awareness of the patient's and family's perceptions of illness and treatment. In viewing the patient as a person with his or her own unique experience, nurses were challenged to seek out the patient's perspective. To reinforce this approach, recent publications by cancer survivors were included in the course bibliography. (Frank, 1992; Leigh, 1992).

In the clinical area, nurses were expected to explore the patient's perspective as part of their overall assessment, and to collaborate with the patient and family to set goals and develop a plan to achieve these goals. The nurse was assisted by the primary nurse and head nurse on the unit, and by the advisor during individual weekly meetings. Written fieldnotes which document the study and analysis of clinical work were completed each week to facilitate the analysis of clinical practice.

\section{Developing knowledge: Pathophysiology, diagnostic tests, therapeutic regimes}

Members of the multidisciplinary team presented classes on a variety of topics. For instance, during the fifth week of the course, the breast team presented the treatment of breast cancer. Here, the multiple methods of surgery, radiotherapy and chemotherapy were reviewed. Building on this foundation, the effects of cancer, such as the impact on body image, were examined in the classroom. Here, nurses explored ways to help the patient and family adapt to body image changes.

Brief site visits to diagnostic test centres, such as nuclear medicine and endoscopy, allowed nurses to learn about how tests were done and interpreted. One-day observational experiences were also available in certain diagnostic and treatment areas. In these areas, nurses accompanied patients through procedures and observed the preparation and testing. For example, nurses with an interest in learning about breast cancer prevention, diagnosis and management visited the outpatient breast centre. Here, nurses observed patients undergoing mammography, breast biopsy, and learning breast self-examination. This experience enabled nurses to observe the patients experiencing these events first-hand.

\section{Developing knowledge and skills to nurse patients}

Classes were given on the nursing care associated with the physical, psychosocial and spiritual needs of the patient with cancer. Particular emphasis was placed on nursing interventions to prevent and manage treatment side effects and toxicities, and other illness-related symptoms such as pain. Through lectures and discussions of nursing approaches to the care of patients with cancer, and by reading selected references, nurses began to identify new approaches to care which were based on research findings. Through clinical work with a small group of patients, new assessment skills and interventions were tested and evaluated.

For instance, a half-day workshop was given on coping with cancer. During this session, the coping-skills-based psychosocial intervention studied by Edgar, Rosberger \& Nowlis (1992) was presented by Ms L. Edgar, guest lecturer in the course. Students were introduced to the rationale for intervention, research findings, and how they could implement this intervention in their own practice. Advisors assisted the students to try out the psychosocial intervention in their clinical practice and to evaluate the impact.

Throughout their clinical experience, nurses practised assessment skills and expanded their repertoire of interventions. Skill labs provided an opportunity for the nurse to learn new skills which are particular to oncology. Management of venous access devices and the administration of chemotherapy are two of the skills that nurses practised in a simulated environment. Skill acquisition was reinforced in the clinical area with appropriate support and supervision.

Weekly clinical seminars facilitated the analysis of clinical practice and the development of research-based practice. During the seminar, nurses presented an overview of selected references in relation to their clinical practice.

\section{Developing knowledge and skills to nurse families}

Woods, Lewis \& Ellison (1989) describe the experience of cancer as a family experience. Family members' concerns about cancer vary with their roles, and members cope with their experience in different ways. Families also influence the adjustment of the person with cancer and are important sources of support. Lewandowski and Jones (1988) recognize the impact of the diagnosis of cancer on the family. They state that a cancer diagnosis in any member of the family disrupts the family's homeostatic balance and imposes change. Therefore, nursing interventions must focus on the patient as a member of a family system. The unit of care is the family.

With this theory as a springboard, a series of eight classes was presented on learning to work with families. The classes covered six family nursing topics (Figure Two). In addition, nurses had the opportunity to learn about family members' experiences through panel discussions in which family members participated. Nurses practised skills in the classroom such as family interviewing and used these skills in their clinical practice with families. The objective of a written family assignment was to help nurses integrate theory with practice. The assignment consisted of a five-page paper on the assessment and plan for a family whom they have followed during the course. The Calgary Family Assessment Model (Wright and Leahey, 1984) provided a framework for this assignment. Nurses reported that the assignment helped them see the family as a whole, and was instrumental in linking all aspects of their work with families.

Understanding collaborative practice within the multidisciplinary team

Oncology care in a tertiary care centre is delivered by a multitude of professionals. Hence, it is essential for nurses to work effectively

Figure Two: Family nursing topics

- family assessment

- interviewing skills

- family communication

- family coping

- multicultural perspectives

- interventions with families 
with the multidisciplinary team. To facilitate collaborative practice with the team, nurses must develop skills in leadership, bargaining and negotiating (Ornstein, 1990). Nurses require knowledge about team dynamics and effective communication skills to be productive team members.

With this in mind, classes were given on the theoretical concepts of multidisciplinary teamwork in the health care setting, including the benefits and obstacles to teamwork. Group dynamics and communication skills were studied. Nurses were asked to attend formal multidisciplinary interactions, such as rounds, and to study the interactions among the group. In clinical practice, they were to identify key members of the team for their particular patients, examine their own role, and participate as team members.

Multidisciplinary team members, including health care professionals and volunteers, participated as faculty in the course. This served the dual role of imparting knowledge and demonstrating the interdependence of the various disciplines on a peer level.

\section{Developing coping resources}

It is oncology nurses who provide care to patients with life-threatening illnesses. Beaton and Degner (1990) stated that nurses are not hardened or emotionally numbed by daily exposure to death and dying; rather, they are deeply moved. As described by one nurse in their study, working with life-threatened patients requires "a maturity unrelated to age". (p.22)

In order to successfully withstand the stresses and strains of helping patients and their families deal with cancer, nurses must recognize and express their own feelings, and develop their own personal resources to cope. Nurses are better prepared to care for patients if they can deal with their own feelings and understand their source. Nurses who become overwhelmed with their own feelings will be poorly equipped to aid others.

Attempts were therefore made to assist students to address their own feelings. Experiential small group sessions in the course permitted them to share feelings, develop self-awareness and provide mutual support. Two full days during the first week of the course were devoted to this. Working in dyads and small groups, nurses identified

\section{Table Two: Clinical practice areas of students} upon entry to the course

Clinical area

Surgery

general surgery

urology

gyn/oncology

orthopaedics

CVT surgery

Medicine

medicine/AIDS

medical oncology

palliative care

plasmapheresis

Students Number (\%)

Ambulatory care radiation oncology head and neck clinic

Other combined med. surg. home care liaison psychiatry urology research private agency not employed

Total 37 (100) sources of satisfaction in working in oncology as well as situations that were difficult. The leaders used group process strategies to assist the group to identify and understand their feelings and to describe sources of support. Continued emphasis was placed on this during the weekly clinical seminars. Prior to discussion of clinical practice issues in these seminars, nurses discussed their feelings and possible coping strategies.

\section{Exploring professional issues}

The professional nursing topics that were discussed in the course were research utilization, ethical issues, leadership in practice, and career planning. In addition to specific classes devoted to these issues, they recurred as themes throughout the clinical seminars.

Another professional issue is that of initiating change. Valencius (1980b) reported that graduates of an oncology continuing education program encountered barriers in the work environment that inhibited their use of new knowledge. Barriers included administrative policies and other non-nurse health professionals. This finding suggests that nurses require assistance to implement changes in their practice.

Strategies to implement change were addressed in a class on clinical leadership. Here we explored how to promote change in practice both on a personal and group level. Nurses were assisted to identify obstacles in their own work settings and to develop a plan of action to implement changes in practice. Resource persons were identified in their own settings who could assist them to use new knowledge and skills.

During the class on career planning, nurses examined the steps in professional career planning and explored resources to aid in achieving career goals. Membership and participation in provincial and national oncology associations were actively encouraged as ways to foster professional growth and networking.

\section{Evaluation}

\section{Student evaluation}

Course objectives and individual student learning objectives formed the framework for evaluation of the student. Students were evaluated on their clinical performance, family nursing assignment, and case presentation. Students completed the written case presentation at the end of the course to facilitate the integration of new knowledge and skills. A particular patient and family situation was discussed in relation to a specific patient care issue. Patient care issues included hope, loss and spirituality. The nurse was asked to analyze the issue objectively, to integrate literature with clinical data, and to describe the relevant nursing care plan. This assignment was also presented orally to the student group.

Advisors monitored students' clinical practice throughout the course and gave feedback at their weekly meetings. Both advisors and students completed clinical evaluation forms at the end of the course. During the final evaluation, emphasis was placed on the strengths of the student and on areas where the nurse might continue to develop. For instance, if a nurse demonstrates the ability to assess a family, yet may need to learn more about family nursing interventions, it is the advisor who would recommend resources to help the nurse to learn more about family nursing interventions.

A graduation was held on the last day of the course and all speakers and staff from the clinical practice settings were invited. The achievements of graduates were recognized by the awarding of certificates by the director of continuing education. In addition, the director of the medical advisory committee of the Cedars Cancer Institute awarded each graduate with a pin symbolizing the Cedars emblem. The graduation was an important event that recognized the accomplishments of the graduates.

\section{Course evaluation}

To date, 37 nurses have completed the course. Of these $37,29(78 \%)$ were staff nurses in our hospital. The other seven were staff nurses from other Montreal hospitals and agencies. One nurse was not employed prior to the course. Table Two describes the clinical practice areas of students upon entry to the course. Nurses have come from a wide variety 
of practice settings, although the largest number of students came from general surgical units.

The educational preparation of students was examined (Table Three). The basic nursing preparation education of the majority of students $(78 \%)$ was the hospital or college nursing diploma. Eight $(22 \%)$ of the diploma-prepared nurses had other degrees or certificates, including a post-basic degree in nursing.

Students' experience in nursing ranged from less than one year to 40 years (Table Four). The largest number of students had more than one but less than five years of experience.

This diversity in clinical practice areas, educational preparation and nursing experience highlights that the course was able to accommodate nurses from all levels of educational backgrounds. Since the clinical component was flexible, it permitted the clinical experience to be individually tailored to the needs of each student. This flexibility was an important factor in the overall success of the course.

Course evaluations completed by graduates at the end of the course indicate their satisfaction. Twenty-five of the 37 graduates $(68 \%)$ submitted course evaluations. A review of the evaluations identified six course components that were of particular value to the learners. These components were: Self-directed learning with advisor support, patient participation in panel presentations, work with families, the focus on nurses' learning to cope with their own feelings, lectures and seminars. One nurse described the importance of the advisor in helping her to achieve her goals: "My advisor facilitated learning by using the strategies of acknowledging my feelings, reinforcing my strengths, involving other resources, giving information and being available as needed and regularly every week."

Follow-up of graduates was maintained to determine where nurses worked immediately after completing the course and six months later. Thirty-four graduates returned to their previous nursing positions at the end of the course. Two graduates from outside of our hospital entered the course with the intention of assuming positions on our staff. One was recruited to the palliative care unit and the other for a general surgical unit. One graduate was lost to follow-up. At the six-month interval, 30 nurses had remained in their positions. Four nurses from within our hospital had transferred to new staff nurse positions.

The course was seen to be a significant influencing factor in preparing three of these four nurses for their new positions in outpatient oncology and the breast centre. The results of the follow-up of students suggest that the course facilitated the retention of staff nurses.

The impact of the course on clinical practice has been described as the most significant outcome of the course. Informal discussions with graduates revealed that they felt more competent to care for patients with cancer and their families after the course than before. They felt that they had a better understanding of the experience of illness for patients and families and were more sensitive to their needs. They also indicated that they felt able to cope with their own feclings.

\section{Table Three: Students' educational preparation}

$\begin{array}{cl}\text { Basic nursing preparation } & \text { Number (\%) } \\ \text { Diploma } & 29(78) \\ \text { Baccalaureate } & 8(22) \\ \begin{array}{c}\text { Other education } \\ \text { Baccalaureate }\end{array} & \text { Number (\%) } \\ \text { nursing } & 2(5) \\ \text { community nursing } & 1(3) \\ \text { applied social sciences } & 1(3) \\ \text { psychology } & 1(3) \\ \text { fine arts } & 1(3) \\ \text { Certificate } & 1(3) \\ \quad \text { public health } & 1(3) \\ \text { community nursing } & 8(22)\end{array}$

Many of the graduates have received recognition from their colleagues and head nurses by being consulted as resource persons in oncology nursing. Many have presented educational sessions on their own units and at nursing rounds. One recent graduate is currently evaluating the need for a support group for patients with prostate cancer. The Cedars Cancer Institute has continued to acknowledge the achievements of the course graduates through the continued provision of financial support for educational bursaries.

\section{Formal evaluation}

A formal evaluation study is now in progress to examine the learning outcomes of the graduates. This descriptive study compares the learning outcomes of graduates with a matched control group of nurses who have not taken the course. Data on the content of nurses' assessments of patients and their communication skills with patients are being examined. The results of this study will be used to guide further course development.

\section{Future directions}

The planning and ongoing development of the course continues at two levels. First, a multidisciplinary advisory committee meets quarterly to make recommendations to the nursing committee on the continuing development of the course. Membership includes a patient and family representative, a physician, nursing representatives from inpatient and ambulatory oncology settings, the director of continuing education and the coordinator of the course.

Second, the nursing course planning committee reviews the recommendations of the advisory committee and specific curriculum issues. Course content, learning activities and evaluation methods are examined following each course and are modified to reflect current nursing practices in oncology. The committee has also developed marketing activities to promote awareness of the course.

Furthermore, we are experimenting with a new strategy that provides nurses with a tool to transfer knowledge from theory to practice in a measurable form. This theory was described by Barg et al. (1992a, 1992b). Participants in a three-day program for health care providers caring for persons with cancer were asked to identify aspects of their current practice that they felt could be enhanced based on what they learned in the course. At the completion of the course, participants were asked to select one priority item that represented a gap in their practice, and to suggest a contract that represented a goal they would like to achieve by addressing this gap. Participants were asked to design an approach to meet this goal and to pinpoint resources and barriers in implementing their approach. A four-month follow-up evaluation showed that a high percentage of participants did adopt innovations in spite of obstacles that they may have encountered.

This strategy will be implemented in the next oncology nursing course to assist nurses to transfer learning from the course to their clinical practice. The course coordinator is conducting a four-month follow-up of the implementation of this innovation.

\section{Conclusion}

This course in oncology nursing has provided an opportunity for nurses to expand their knowledge and skills in cancer nursing. The use of a self-directed format has made it possible to accommodate the learning needs of nurses with varied clinical experience and

Table Four: Years of active nursing experience

$\begin{array}{cl}\text { Years of experience } & \text { Number (\%) } \\ 0-1 & 6(16) \\ >1-5 & 11(30) \\ >5-10 & 6(16) \\ >10-20 & 5(14) \\ >20-30 & 8(22) \\ >30-40 & 1(3)\end{array}$


educational preparation. This mix of students has enhanced peer teaching. Ongoing mentor relationships have also developed from the association between students and advisors. In their new roles as mentors, the advisors can continue to be sources of guidance for the oncology course graduates. While the content presented in the course has been very valuable, it is becoming apparent that it is the process of learning that will uitimately contribute to nurses' continued professional development and competence.

\section{References}

1. Barg, F.K., McCorkle, R., Robinson, K., Yasko, J., Jepson, C., McKeehan, K. (1992a). Gaps and contract: Evaluating the diffusion of new information. Part I. A description of the strategy. Cancer Nursing, $15,401-405$.

2. Barg, F.K., McCorkle, R., Robinson, K., Yasko, J., Jepson, C., McKeehan, K. (1992b). Gaps and contract: Evaluating the diffusion of new information. Part II. The measurement of the strategy. Cancer Nursing, 15, 406-414.

3. Beaton, J., Degner, L. (1990). Life and death decisions: The impact on nurses. The Canadian Nurse, 86(3), 18-22.

4. Canadian Association of Nurses in Oncology. (1990). Submission to the Cancer 2000 Task Force.

5. Carnevali, D.L., Reiner, A.C. (1990). The cancer experience: Nursing diagnosis and management. Philadelphia: J.B. Lippincott.

6. Edgar, L., Rosberger, Z., Nowlis, D.H. (1992). Coping with cancer during the first year after diagnosis. Cancer, 69, 817-828.

7. Frank, A.W. (1991). At the will of the body: Reflections on Illness. New York: Houghton Mifflin.

8. Gottlieb, L., Rowat, K. (1987). The McGill model of nursing: A practice derived model. Advances in Nursing Science, 9(4), 51-61.

9. Groenwald, S.L. (Ed.). (1987). Cancer nursing: Principles and practices. Boston: Jones and Bartlett.

10. Itano, J.K., Pierce, M., Masten, K.B., Whitley, M.J. (1992). Developing the oncology nurse from novice to expert. Oncology Nursing Forum, 19, 1233-1234.

11. Leigh, S.(1992). Myths, monsters and magic: Personal perspectives and professional challenges of survival. Oncology Nursing Forum, $19,1475-1480$.

12. Lewandowski, W., Jones S. (1988). The family with cancer: Nursing interventions throughout the course of living with cancer. Cancer Nursing, 11, 313-321.

\section{Acknowledgements}

The author would like to thank her colleagues on the core planning committee: Dr. B.L. Smith, director of continuing education in nursing, Patricia Boston, Carol Burnett, Miriam Dattel, Jacques Fortin, Myriam Guay, Ann Lynch, Joan MacDonald, France Morissette, Catherine Oliver and Françoise Picard. Sincere thanks is extended to Gwen Vineberg and Susan Fox for their assistance in preparing this paper.
13. Miaskowski, C. (1990). The future of oncology nursing: A historical perspective. Nursing Clinics of North America, 25, 461-473.

14. Nevidjon, B., Deatrich, J. (1985). An oncology clinical elective. Oncology Nursing Forum, 12(5), 57-59.

15. Nielsen, B.B., Miaskowski, C.A. (1987). The influence of an oncology nursing continuing education program on nursing practice. The Journal of Continuing Education in Nursing, 18, 193-199.

16. Ornstein, H.J. (1990). Collaborative practice between Ontario nurses and physicians: Is it possible? Canadian Journal of Nursing Administration, 3(4), 10-14.

17. Quinn-Casper, P., Holmgren, C. (1987). Enhancing cancer nursing concepts in undergraduate curricula. Cancer Nursing, 10, 274-278.

18. Snyder, C.C. (1986). Oncology nursing. Boston: Little, Brown \& Company.

19. Stolte, M.M., Goss, C.L., Lim, S.S.F.(1988). An oncology nursing residency program: Meeting a continuing education need. The Journal of Education in Nursing, 19, 252-257.

20. Valencius, J. (1980a). Impact of a continuing education program in cancer nursing. Part I: Results affecting patient care. The Journal of Continuing Education in Nursing, 11(2), 14-18.

21. Valencius, J. (1980b). Impact of a continuing education program in cancer nursing. Part II: Results affecting the learner. The Journal of Continuing Education in Nursing, 11(3), 23-27.

22. Woods, N., Lewis, F.M., Ellison, E.S. (1989). Living with cancer: Family experiences. Cancer Nursing, 12, 28-33.

23. Wright, L.M., Leahey, M. (1984). Nurses and families: A guide to family assessment and intervention. Philadelphia: F.A. Davis. 24. Ziegfeld, C.R. (Ed.). (1987). Core curriculum for oncology nursing. Philadelphia: W.B. Saunders.

\section{Correction}

In Volume Three, Number Three, there was a spelling error in the article on page 116 by Susan Galloway, Natalie Bubela, Ann McKibbon, Elizabeth McKay and Eleanor Ross. The title of the article should have read: "Perceived information needs and affect of symptoms on activities after surgery for lung cancer".

We apologize for any inconvenience this misprint may have caused.

Dans le "Volume Three, Number Two", une erreur d'orthographe s'est glissée dans la version anglaise de l'article de la page 116 présenté par Susan Galloway, Nathalie Bubela, Ann McKibbon, Elizabeth McKay et Eleanor Ross. Le titre correct de l'article aurait dû être: "Perceived information needs and affect of sympoms on activities after surgery for lung cancer".

Nous vous prions de nous excuser pour tout inconvénient que notre faute typographique a pu causer.

\section{Announcing CNF/CANO scholarships}

Are you looking for funding to pursue your education? There are several CNF/CANO scholarships available to CANO members pursuing further education at the baccalaureate and Masters levels.

For information and application forms for these and other scholarships, please contact:

The Canadian Nurses Foundation, 50 Driveway

Ottawa, Ontario, K2P 1E2

Telephone: (613) 237-2133

Fax: (613) 237-3520

\section{Annonce des bourses FIIC/ACIO}

Êtes-vous à la recherche de fonds pour financer vos études? Plusieurs bourses FIIC/ACIO sont offertes aux membres de PAClO qui poursuivent des études au niveau du baccalauréat ou de la maitrise.

Pour plus d'information ainsi que les formulaires de demande:

La Fondation des infirmières et infirmiers du Canada, 50, Driveway

Ottawa (Ontario) K2P IE2

Téléphone: (613) 237-2133

Télécopieur: (613) 237-3520 